\title{
Latex proteins downregulate inflammation and restores blood-coagulation homeostasis in acute Salmonella infection
}

\author{
Brandon Ferraz Sousa', Ayrles Fernanda Brandão da Silva', José Vitor Lima-Filho², \\ Anderson Gomes Agostinho', Denise Nunes Oliveira ${ }^{3}$, Nylane Maria Nunes de Alencar4, \\ Cleverson Diniz Teixeira de Freitas ${ }^{1}$, Márcio Viana $\operatorname{Ramos}^{1 /+}$
}

${ }^{1}$ Universidade Federal do Ceará, Departamento de Bioquímica e Biologia Molecular, Fortaleza, CE, Brasil

${ }^{2}$ Universidade Federal Rural de Pernambuco, Departamento de Biologia, Recife, PE, Brasil

${ }^{3}$ Universidade de Fortaleza, Departamento de Patologia, Fortaleza, CE, Brasil

${ }^{4}$ Universidade Federal do Ceará, Departamento de Fisiologia e Farmacologia, Fortaleza, CE, Brasil

BACKGROUND Calotropis procera latex protein fraction (LP) was previously shown to protect animals from septic shock. Further investigations showed that LP modulate nitric oxide and cytokines levels.

OBJECTIVES To evaluate whether the protective effects of LP, against lethal bacterial infection, is observed in its subfractions $\left(\mathrm{LP}_{\mathrm{PII}}\right.$ and $\left.\mathrm{LP}_{\mathrm{PIII}}\right)$.

METHODS Subfractions ( 5 and $10 \mathrm{mg} / \mathrm{kg}$ ) were tested by i.p. administration, $24 \mathrm{~h}$ before challenging with lethal injection (i.p.) of Salmonella Typhimurium. $\mathrm{LP}_{\mathrm{PIII}}(5 \mathrm{mg} / \mathrm{kg})$ which showed higher survival rate was assayed to evaluate bacterial clearance, histopathology, leukocyte recruitment, plasma coagulation time, cytokines and NO levels.

FINDINGS $\mathrm{LP}_{\mathrm{PIII}}$ protected $70 \%$ of animals of death. The animals given $\mathrm{LP}_{\mathrm{PIII}}$ exhibited reduced bacterial load in blood and peritoneal fluid after $24 \mathrm{~h}$ compared to the control. $\mathrm{LP}_{\mathrm{PIII}}$ promoted macrophage infiltration in spleen and liver. $\mathrm{LP}_{\mathrm{PIII}}$ restored the coagulation time of infected animals, increased IL-10 and reduced NO in blood.

MAIN CONCLUSIONS LP ${ }_{\mathrm{PII}}$ recruited macrophages to the target organs of bacterial infection. This addressed inflammatory stimulus seems to reduce bacterial colonisation in spleen and liver, down regulate bacterial spread and contribute to avoid septic shock.

Key words: cytokines - coagulation - haemostasis - nitric oxide - peritoneal cavity

The latex exuded by laticifer plants plays an important role in plant defense against pathogens and herbivores. Secondary metabolites, proteins and peptides, present in laticifer fluids, are expected to act against an incoming infection or predation. This action-specificity means that each group of chemical compounds that composes latex fluids possesses a specific molecular target, inside or outside the plant. ${ }^{(1)}$

For a long time, different parts of the plant Calotropis procera (Aiton) WT Aiton, are being studied for their use in alternative medicine, aiding the treatment of various conditions, including pain, asthma, eczema, mouth bleeding and superficial skin burns. ${ }^{(2)}$ More importantly, the latex from $C$. procera has been studied due to its effects over cellular immunity on various models. These effects include analgesic, anti-inflammatory, proinflammatory, antimicrobial activity, and others. ${ }^{(3,4)}$

doi: 10.1590/0074-02760200458

Financial support: CNPq, CAPES, FUNCAP.

This study is part of the consortium "Molecular Biotechnology of Plant Latex".

+ Corresponding author: r_marcio@hotmail.com

(1) https://orcid.org/0000-0002-8260-4144

Received 04 September 2020

Accepted 09 November 2020
Among the constituents of $C$. procera latex, approximately $85 \%$ of its dry mass is rubber (polyisoprene), while soluble proteins represent around 10\%. Among the soluble laticifer proteins (LP), are peptidases, that degrade substate BANA, and azocasein in neutral $\mathrm{pH}^{(5)}$ The fractionation of the $C$. procera LP, through CMSepharose Fast Flow chromatography and further biochemical characterisation of each obtained subfraction, lead to a better understanding of the composition of the plant's latex proteins, and allowed a more in-depth study of its capacity to affect cellular immunity.

$\mathrm{LP}_{\mathrm{PI}}, \mathrm{LP}_{\mathrm{PII}}$ and $\mathrm{LP}_{\mathrm{PIII}}$ are the subfractions resulting of LP chromatography. ${ }^{(6)} \mathrm{LP}$ was shown to modulate the immune response in various animal models, by reducing histamine leakage, nitric oxide (NO) synthesis, and cytokines release, allowing a complex balance among antiinflammatory and proinflammatory activities depending of specific physiological circumstances. ${ }^{(7,8)}$

Calotropis procera LP was studied for their effect on bacterial infection of human interest. LP did not inhibit growth of Salmonella enterica enterica serovar Typhimurium in vitro, thus, this fraction does not act directly on the bacterium. However, when mice were treated by different inoculation routes, the dose of 60 $\mathrm{mg} / \mathrm{kg}$ of LP given intraperitoneally, fully protected animals against the lethal Salmonella, whereas the administration by oral and subcutaneous routes did not protect the animals. Although the treatment with LP prevented the death of the animals, the study reported that bacteria 
were still present in liver and spleen, causing transient histological damage. The presence of bacteria in bloodstream and target organs of treated animals suggested that LP modulate inflammation, avoiding septic shock.

(9) Further, bacteria clearance was reached after 28 days.

When assessing the influence of LP over the coagulation haemostasis, the intraperitoneal administration of LP abrogated the coagulant reaction caused by Salmonella infection. However, there is no information whether the protective effect of LP against septic shock is restricted to $\mathrm{LP}_{\mathrm{PI}}, \mathrm{LP}_{\mathrm{PII}}$ and $\mathrm{LP}_{\mathrm{PIII}}$ subfractions or whether synergisms may occur.

In another study, the three subfractions $\mathrm{LP}_{\mathrm{PI}}, \mathrm{LP}_{\mathrm{PII}}$ and $\mathrm{LP}_{\mathrm{PIII}}$ were tested for their effect on blood coagulation. The subfractions $\mathrm{LP}_{\mathrm{PII}}$ and $\mathrm{LP}_{\mathrm{PIII}}$ that exhibit proteolytic activity, demonstrated procoagulant activity over human plasma. These two subfractions also exhibited fibrinogenolytic and fibrinolytic effects. Both effects were not observed in $\mathrm{LP}_{\mathrm{PI}}$ that does not possesses peptidases. Worth of note, LP restored to near normality the coagulation time of blood in infected animals. This effect inhibited the disseminated intravascular coagulation, a phenomenon observed in lethal bacteria infection. This study suggested that the peptidases present in $C$. procera latex possess biological activities that may be useful for treatment of coagulation abnormalities. ${ }^{(10)}$

The first attempt to investigate the role of LP subfractions in protection against bacterial infection was performed with $\mathrm{LP}_{\mathrm{Pr}}$. The subfraction $\mathrm{LP}_{\mathrm{PI}}$ was tested against the same Salmonella infection model and some aspects of its action over the immune system was investigated. Animals treated by intraperitoneal route survived the infection challenge. Similar to the LP treatment, $\mathrm{LP}_{\mathrm{PI}}$ induced high bacterial clearance in the bloodstream. mRNA of TNF- $\alpha$ was increased early in treated animals, alongside a reduction in NO contents in the blood. Neutrophil infiltration into the peritoneal cavity was enhanced and it was concluded that this inflammatory stimulus, caused by the $\mathrm{LP}_{\mathrm{PI}}$ administration, may induce phagocytosis of bacteria, affording protection against animal death. ${ }^{(6)}$ However, the mechanism underlying this effect remains unknown.

Although the mechanisms of LP action remain obscure, the ability of this preparation to modulate inflammation has been proved in other relevant inflammatory conditions, including arthritis and chemotherapy. ${ }^{(1)}$ Given this information, LP is shown to be a protein fraction of great pharmacological interest due to its activity over the immune system and inflammation. To better understand the protective effect of LP over the bacterial infection, in this study, the subfractions $\mathrm{LP}_{\mathrm{PII}}$ and $\mathrm{LP}_{\mathrm{PIII}}$ were examined. Some aspects of the effectiveness of subfractions $\mathrm{LP}_{\mathrm{PII}}$ and $\mathrm{LP}_{\mathrm{PIII}}$ were investigated against the same infection model, focusing on the one that yielded the best survival rates in challenge experiments.

\section{MATERIALS AND METHODS}

Latex extraction and processing - Vegetative and reproductive samples of $C$. procera shrubs were identified by specialists of the Herbarium Prisco Bezerra located at the Federal University of Ceará and the materials were deposited under voucher number 32663 . The access and use of this biological resource were performed after registration and legal authorisation according to the current Brazilian law for biodiversity (Agreement $\mathrm{n}^{\mathrm{o}}$ A689147). The latex was collected fresh, following previous methodologies. ${ }^{(7)} C$. procera LP were obtained after centrifugation, dialysis and lyophilisation, of the latex. Aiming to inhibit the proteolytic activity of the LP, iodoacetamide (IAA) was used accordingly. ${ }^{(12)}$ Thus, the latex was also collected on 10 mM IAA solution, instead of distilled water.

Chromatography fractionation - C. procera LP was fractionated through ion-exchange chromatography. A CM-Sepharose Fast Flow matrix was used and equilibrated with $50 \mathrm{mM}$ sodium acetate buffer ( $\mathrm{pH}$ 5.0). LP $(10 \mathrm{mg} / \mathrm{mL})$ was dissolved in the same buffer, followed by centrifugation to remove insoluble material. After loading the sample, the chromatography system was washed with the initial buffer and $\mathrm{LP}_{\mathrm{PI}}$ was recovered. The adsorbed fractions were eluted by increasing the ionic strength of the buffer by adding $0.2 \mathrm{M}$ and $0.3 \mathrm{M}$ of sodium chloride $(\mathrm{NaCl})$, sequentially. Fractions of $2 \mathrm{~mL}$ were collected at $0.5 \mathrm{~mL} / \mathrm{min}$ flow rate. Each fraction had its absorbance read at $280 \mathrm{~nm}$ in a spectrophotometer. Two distinct protein peaks were obtained within salt gradient $\left(\mathrm{LP}_{\mathrm{PII}}\right.$ and $\left.\mathrm{LP}_{\mathrm{PIII}}\right)$, respectively. The processing and fractionation of the latex collected with IAA were performed exactly as described above, in this case the samples were labeled LP${ }_{\mathrm{PII}}$-IAA and $\mathrm{LP}_{\mathrm{PIII}}$-IAA. ${ }^{(10)}$ All the samples were dialysed in distilled water followed by freeze-dry before use. The fractions treated with IAA were checked for absence of proteolysis according to Freitas et al..$^{(5)}$

Protein profile analysis by sodium dodecyl sulphatepolyacrylamide gel electrophoresis (SDS-PAGE) - One dimensional electrophoresis was used to accompany the fractionation steps. Electrophoresis were proceeded according to standard procedures. ${ }^{(13)}$ Molecular mass markers were used for reference [phosphorylase $\beta(97.0 \mathrm{kDa})$, bovine serum albumin $(66.0 \mathrm{kDa})$, ovalbumin $(45.0 \mathrm{kDa})$, carbonic anhydrase $(30.0 \mathrm{kDa})$, trypsin inhibitor $(20.1$ $\mathrm{kDa})$ and $\alpha$-lactalbumin $(14.4 \mathrm{kDa})]$. The runs were executed in constant current of $30 \mathrm{~mA}$ per gel and tension of $110 \mathrm{~V}$ per gel, in an average duration of $2 \mathrm{~h}$ at $25^{\circ} \mathrm{C}$. In each lane, $30 \mu \mathrm{L}$ of each sample diluted to $1 \mathrm{mg} / \mathrm{mL}$ in distilled water was applied. Protein bands were visualised after coloring with Coomassie Brilliant Blue R-250.

Ethics and animals - Adult male Swiss mice (Mus musculus), weighing between 30 and 35 grams, obtained from the Central Animal House of the Federal University of Ceará were used. They were kept in cages, in a room with controlled air temperature of $24^{\circ} \mathrm{C}$ and 12-h day-night cycle, with free access to water and food (standard commercial food from Purina, Paulínia, SP, Brazil). The animals were handled by strictly following the recommendations from the National Council for the Control of Animal Experimentation - CONCEA, after approval by the local institution's Ethic Committee on the Use of Animals (CEUA - UFC, under protocols 5786300718 and 9112020519).

Microorganisms - The systemic infection of Swiss mice was provoked by Salmonella enterica enterica serovar Typhimurium C5 strain, which was a gift by Dr 
Pietro Mastroeni from Cambridge University, UK. The bacteria were activated in Brain Heart Infusion broth at $37^{\circ} \mathrm{C}$ for $18 \mathrm{~h}$ and then cultured in brain heart infusion (BHI) agar for another $24 \mathrm{~h}$ at $37^{\circ} \mathrm{C}$. For bacterial enumeration, after animal infection, samples from infected animals were plated and bacteria were counted at MacConkey agar incubated at $37^{\circ} \mathrm{C}$ for $24 \mathrm{~h}$.

Survival evaluation - To evaluate the protective effect of $C$. procera subfractions, against the bacterial infection model, animals, in experimental groups, received a single administration of 0.2 of $\mathrm{LP}_{\mathrm{PII}}$, $\mathrm{LP}_{\mathrm{PII}}-\mathrm{IAA}, \mathrm{LP}_{\mathrm{PIII}}$ or $\mathrm{LP}_{\mathrm{PIII}}{ }^{-}$ IAA $(5.0$ and $10.0 \mathrm{mg} / \mathrm{kg})$, diluted in phosphate-buffered saline (PBS, $p H$ 7.2), by intraperitoneal route (i.p). The infection model with Salmonella Typhimurium was executed as described by Lima-Filho et al..$^{(9)}$ Thus, $24 \mathrm{~h}$ after the protein administration, the animals were challenged by inoculation of a bacterial suspension of $S$. Typhimurium on $0.2 \mathrm{~mL}$ of sterile PBS via i.p. The bacterial suspension was prepared by diluting previously activated and isolated colonies of $S$. Typhimurium in PBS until attaining a bacterial suspension of $10^{8}$ colony-forming units per milliliter (equivalent of 0.5 absorbance units of optical density at $600 \mathrm{~nm}$ ), which was diluted 100-fold [achieving $10^{6} \mathrm{col}-$ ony-forming unit $(\mathrm{CFU}) / \mathrm{mL}$ ] before inoculation. For survival evaluation, a group of animals received only PBS before infection to serve as control, all animals ( $\mathrm{n}=10$ per group) were infected at once using the same bacterial suspension. After inoculation, all groups were observed daily up to 7 days. Behavioral alterations, such as changes in posture, mobility, facial expression, grooming and vocalisation and distress were evaluated. The treatment that showed the best survival rate continued to be used in the following experiments. The results were expressed as percent survival of each group along seven days, a log-rank test was used to assess statistical differences.

Experimental design - The following analyses were done using $\mathrm{LP}_{\mathrm{PII}}$ at the dose of $5 \mathrm{mg} / \mathrm{kg}$. Thus, the animals were randomly divided into four groups. Two PBS groups were formed. One PBS group $(n=6)$ consisted of animals that only received $0.2 \mathrm{~mL}$ of PBS i.p. The other PBS group $(n=12)$ was formed with animals that received PBS i.p. and were infected $24 \mathrm{~h}$ later. Similarly, two $\mathrm{LP}_{\text {PIII }}$ groups were formed, a first one $(\mathrm{n}=12)$ that consisted of healthy animals that only received LPPIII i.p. The other group $(\mathrm{n}=12)$, animals received $\mathrm{LP}_{\mathrm{PIII}}$ i.p. and were infected $24 \mathrm{~h}$ later. Except for the healthy PBS group, all other groups had half of their animals euthanised $24 \mathrm{~h}$ after inoculation/administration $(\mathrm{n}=6)$ and the other half were euthanised $72 \mathrm{~h}$ post inoculation/ administration $(n=6)$. The groups that were infected, received an intraperitoneal inoculation of bacterial suspension $\left(0.2 \mathrm{~mL}, 10^{6} \mathrm{CFU} / \mathrm{mL}\right.$ in PBS). This design was repeated three times under the same conditions, every time different materials were collected to run different analysis, always respecting the ethics by executing as most assays as possible with the least number of animals.

Bacterial enumeration - Infected mice were anesthetised, by administering $0.2 \mathrm{~mL}$ of a solution of Xylazine $(10 \mathrm{mg} / \mathrm{kg})$ and Ketamine $(100 \mathrm{mg} / \mathrm{kg})$ by intraperitoneal route. Blood samples of approximately $800 \mu \mathrm{L}$ were col- lected from the retro-orbital plexus of each animal under anesthesia, followed by euthanasia. Afterwards, the abdominal cavity was opened, and the liver and spleen were aseptically removed. Peritoneal fluid was obtained by washing the abdominal cavity with $3 \mathrm{~mL}$ of sterile PBS containing $1 \%$ ethylenediaminetetraacetic acid (EDTA). All analyses were done individually from the material collected from each animal. Bacterial enumeration in the blood, fluid and organs was done after dilution in PBS and aliquots were plated onto MacConkey agar for $24 \mathrm{~h}$ of incubation at $37^{\circ} \mathrm{C}$. Results were expressed as CFU per gram of organ or milliliter of blood. One-way analysis of variance (ANOVA) was employed with Bonferroni posthoc test to evaluate statistical differences.

Cells count - Blood and peritoneal fluid collected as described above was used to count leukocytes as previously reported by Souza and Ferreira. ${ }^{(14)}$ Total number of leukocytes was counted followed by differential count of neutrophil cells. The results were expressed as $10^{3}$ cells per milliliter of plasma or fluid. ANOVA was employed with Bonferroni post-hoc test to evaluate statistical differences.

Histological analyses - After liver and spleen removal, a small section of the organs was immersed into $10 \%$ buffered formaldehyde ( $\mathrm{pH}$ 7.2) for fixation. This material was dehydrated and diaphanised before inclusion in paraffin for cutting slices of $5 \mu \mathrm{m}$ thickness in a microtome, to be mounted into microscope glass slides. The microscope slides were dyed with hematoxylin-eosin, for analysis of inflammatory infiltration and general damage. A histological report of each group was elaborated after a blind unbiased reading of at least three different slices of every organ of each animal, by a pathologist, in look for signs of organ architecture damage and presence of inflammatory infiltrate.

Measuring cytokines in plasma and peritoneal fluid - The measurement of TNF- $\alpha$, IL-1 $\beta$ and IL-10 in blood plasma and peritoneal fluid was performed only in animals euthanised within $24 \mathrm{~h}$, due to experimental constrains. Mouse enzyme-linked immunosorbent assay (ELISA) kits were used (R\&D Systems), the assays were performed strictly following manufacturer's instructions. ANOVA was employed with Bonferroni post-hoc test to evaluate statistical differences.

Measuring of NO in plasma and peritoneal fluid The levels of NO in plasma and peritoneal fluid samples were calculated indirectly, by measuring nitrate concentrations, through the conversion of nitrate to nitrite, by means of the enzyme nitrate reductase. ${ }^{(15)}$ The plasma and peritoneal fluid were obtained as previously described. The material was kept on ice for up to $8 \mathrm{~h}$, when the assay was executed. The samples were incubated with $\mathrm{KH}_{2} \mathrm{PO}_{4}$ buffer ( $\mathrm{pH}$ 7.5) containing nitrate reductase, in 96-well plates. A standard curve of sodium nitrate was processed alongside the samples. After 12 $\mathrm{h}$, the Griess reagent was added to the plate. The absorbances were read at $560 \mathrm{~nm}$. The results were expressed as $\mu \mathrm{M}$ of $\mathrm{NO}^{3-} / \mathrm{NO}^{2-}$. ANOVA was employed with Bonferroni post-hoc test to evaluate statistical differences. 
Plasma coagulation time - The blood of the previously described groups was collected in $0.11 \mathrm{M}$ sodium citrate and centrifuged at $500 \mathrm{~g}$ for $15 \mathrm{~min}\left(20^{\circ} \mathrm{C}\right)$ to obtain the plasma. The clot formation was induced by addition of $30 \mu \mathrm{L}$ of $0.25 \mathrm{M} \mathrm{CaCl}_{2}$ to the plasma. The coagulant activity was assessed by measuring the time between the addition of calcium chloride and the formation of a visible clot in the samples. Prothrombin time (PT) and activated partial thromboplastin time (aPTT) haemostasis tests were used (LABTEST Ref.: 501 and 502 respectively), and manufactures instructions were followed accordingly. Coagulation time was measured in a coagulometer (QUICK-TIME, DRAKE). Results were expressed as coagulation time in seconds.

Statistical analyses - All statistical analyses were done using GraphPad Prism software version 8.0.2. Survival experiments were analysed using Mantel-Cox log rank test. For all the other experiments, ANOVA was employed with multiple comparison post hoc Bonferroni corrections. Significant differences were noted when $\mathrm{p}$ $<0.05$ in all tests. In all cases, results are the mean \pm standard error of mean of at least three independent experiments or measurements.

\section{RESULTS}

Latex collection, processing, and fractionation - The latex extraction, processing and fractionation were successful as shown by the chromatography profile and SDSPAGE (Fig. 1). LP has at least seven major distinguishable proteins, while $\mathrm{LP}_{\mathrm{PII}}$ has three major distinguishable proteins and $\mathrm{LP}_{\mathrm{PIII}}$ has four. The subfraction $\mathrm{LP}_{\mathrm{PIII}}$ exhibits a well-distinguished major protein, not detectable in $\mathrm{LP}_{\mathrm{PII}}$, with relative molecular mass near to $30 \mathrm{kDa}$. The treatment with IAA did not change the protein profile of any of the samples (Fig. 1). This are confirmatory results already available in the preceding literature ${ }^{(12)}$ that ensure the identification of each preparation.

Survival evaluation of $L P_{P I I}$ and $L P_{P I I}$ administration - In all infected animals that did not receive treatment or that were treated with $\mathrm{LP}_{\mathrm{PII}}$ or $\mathrm{LP}_{\mathrm{PII}}-\mathrm{IAA}$, it was observed behavioral changes and distress, such as hunched posture, placid behavior, decreased mobility, pointed ears and orbital tightening. However, survived animals treated with $\mathrm{LP}_{\mathrm{PIII}}$ or $\mathrm{LP}_{\mathrm{PIII}}$-IAA did not show behavioral alterations.

All animals from infected PBS group died within 72 h. The i.p. administration of $\mathrm{LP}_{\mathrm{PII}}$ and $\mathrm{LP}_{\mathrm{PIII}}$ increased the resistance of the animals to the lethal bacterial infection, in different degrees (Fig. 2). The animal group treated with $\mathrm{LP}_{\mathrm{PIII}}(5 \mathrm{mg} / \mathrm{kg})$ showed $70 \%$ survival rate after seven days, followed by $\mathrm{LP}_{\text {PIII }}$-IAA $(5 \mathrm{mg} / \mathrm{kg})$, with $40 \%$ survival. Treatment with either $\mathrm{LP}_{\mathrm{PII}}$ or $\mathrm{LP}_{\mathrm{PII}}$-IAA was less efficient, with only $20 \%$ survival. The increase in concentration to $10 \mathrm{mg} / \mathrm{kg}$ reduced survival in all groups, after seven days. In sight of these results, further experimentations were carried out using $\mathrm{LP}_{\mathrm{PIII}}(5 \mathrm{mg} / \mathrm{kg})$.

Effect of treatment with $L P_{P I I}$ over cell immunity in face of bacterial infection - In the peritoneal cavity (Fig. 3), the administration of $\mathrm{LP}_{\mathrm{PIII}}$ induced a leukocyte migration in both, healthy and infected mice. However, this effect was transient in healthy and only detected within $24 \mathrm{~h}$ while it was 2-fold increased after $72 \mathrm{~h}$ in infected animals. In the blood (Fig. 3), the administration of $\mathrm{LP}_{\text {PIII }}$ in healthy mice caused a slight leukopenia only detected within $72 \mathrm{~h}$. During infection, the animals that received $\mathrm{LP}_{\mathrm{PIII}}$, had a mild leukopenia within $24 \mathrm{~h}$, similar to the infected PBS group (Fig. 3).
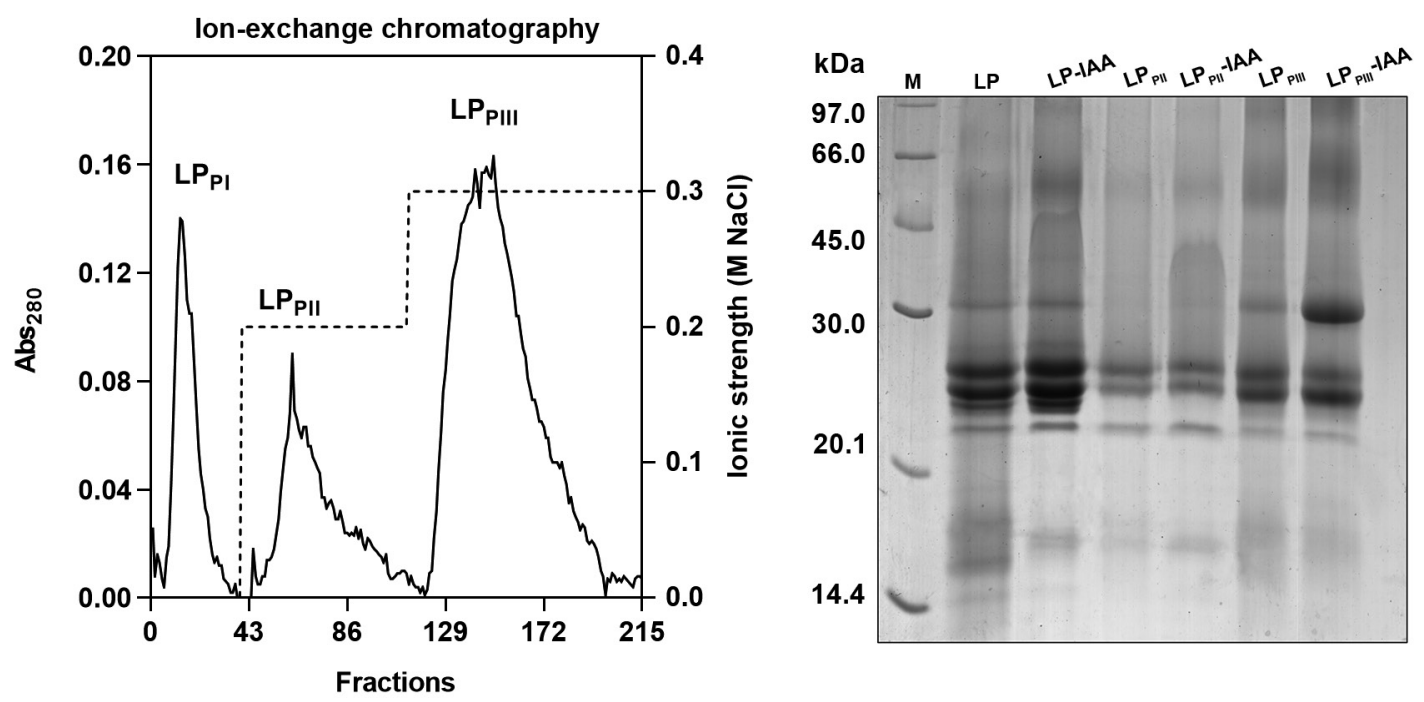

Fig. 1: chromatography and sodium dodecyl sulphate-polyacrylamide gel electrophoresis (SDS-PAGE) of Calotropis procera LP and its subfractions. The panel on the left contains an Ion-exchange chromatography in CM-Sepharose Fast Flow column performed at $\mathrm{pH} 5.0$ of $C$. procera $\mathrm{LP}$. Subfractions $\mathrm{LP}_{\mathrm{PII}}$ and $\mathrm{LP}_{\mathrm{PIII}}$ were eluted by increasing ionic strength by adding $0.2 \mathrm{M}$ and $0.3 \mathrm{M}$ of $\mathrm{NaCl}$ to elution buffer, respectively. The right panel shows the protein profiles of $\mathrm{LP}, \mathrm{LP}_{\mathrm{PII}}$ and $\mathrm{LP}_{\mathrm{PUI}}$ and they after iodoacetamide (IAA) treatment. M: molecular weight markers: $97.0 \mathrm{kDa}$ : phosphorylase $\beta ; 66.0 \mathrm{kDa}$ : albumin; $45.0 \mathrm{kDa}$ : ovalbumin; $30.0 \mathrm{kDa}$ : carbonic anhydrase; $20.1 \mathrm{kDa}$ : trypsin inhibitor and $14.4 \mathrm{kDa}$ : $\alpha$-lactalbumin. 

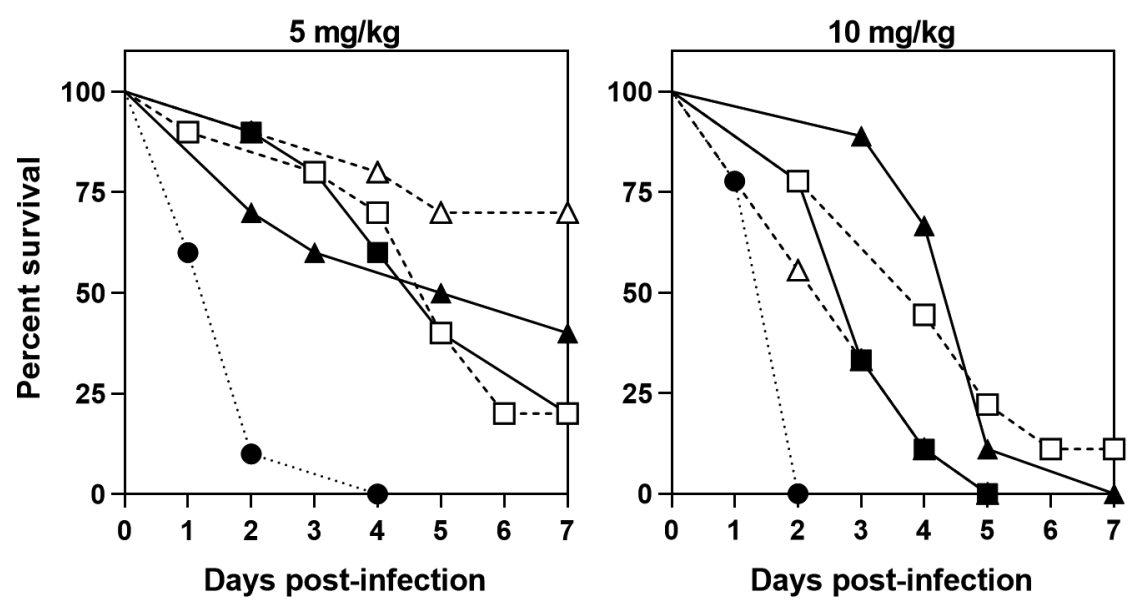

-. PBS - $\square-$ LP PII

LP $P_{\mathrm{PII}}-\mathrm{IAA}-\Delta^{--}$LP $\mathrm{PIII}$

LPPIII-IAA

Fig. 2: time-course of survival of animals treated with LP subfractions against lethal infection of Salmonella enterica serovar Typhimurium. Animals were treated intraperitoneally with $\mathrm{LP}_{\mathrm{PII}}, \mathrm{LP}_{\mathrm{PII}}-\mathrm{IAA}, \mathrm{LP}_{\mathrm{PIII}}$ or $\mathrm{LP}_{\mathrm{PIII}}-\mathrm{IAA}(5$ and $10 \mathrm{mg} / \mathrm{kg}) 24 \mathrm{~h}$ before bacterial inoculation $[0.2 \mathrm{~mL}$, $10^{6}$ colony-forming unit $\left.(\mathrm{CFU}) / \mathrm{mL}\right]$. Animals were observed for seven days. $(\mathrm{p}<0.05 ; \mathrm{n}=10$; Mantel-Cox $\log$ rank test).
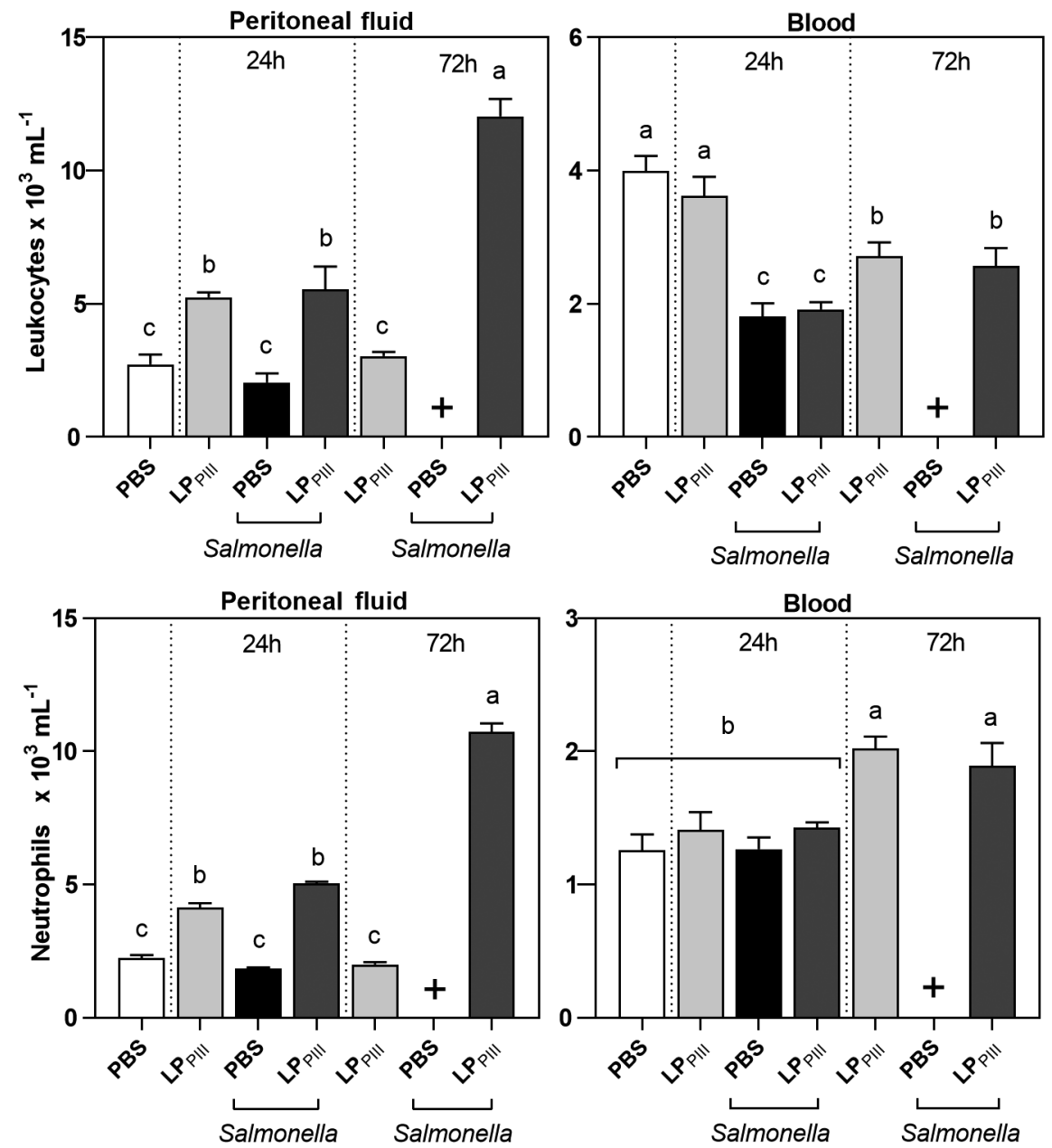

Fig. 3: leukocyte and neutrophil count in the peritoneal cavity and blood. Swiss mice were treated (i.p.) with Calotropis procera $\mathrm{LP}_{\mathrm{PIII}}(5 \mathrm{mg} /$ $\mathrm{kg}) 24 \mathrm{~h}$ before Salmonella Typhimurium inoculation $\left[0.2 \mathrm{~mL}, 10^{6}\right.$ colony-forming unit $\left.(\mathrm{CFU}) / \mathrm{mL}\right]$. Leukocyte and neutrophil enumeration were evaluated 24 and $72 \mathrm{~h}$ after infection. The $(+)$ sign indicated that all animals from that group died. Results are expressed as mean \pm standard error of mean (SEM) cells. Different letters indicate statistically significant differences $(\mathrm{p}<0.05 ; \mathrm{n}=8$; one-way analysis of variance (ANOVA) - Bonferroni test). 
When comparing the number of neutrophils (Fig. 3) to the total number of leukocytes in the peritoneal cavity, it is noted that more than $85 \%$ of those leukocytes were neutrophils in every group, meaning that i.p. administration of $\mathrm{LP}_{\mathrm{PIII}}$ caused neutrophil infiltration to the peritoneal cavity after 24 and $72 \mathrm{~h}$ of infection. When analysing the number of neutrophils in the blood, no change was observed in any group within $24 \mathrm{~h}$ of infection. However, there was a decrease in total leukocyte counts in infected groups within $24 \mathrm{~h}$, meaning that other white blood cells, such as lymphocytes, decreased in number, this relative lymphopenia is reported in cases of typhoid fever. ${ }^{(16)}$

The i.p. administration of $\mathrm{LP}_{\mathrm{PIII}}$ did not alter leukocyte in the blood but increased in the peritoneal cavity of healthy animals. However, this effect increased within 24 and $72 \mathrm{~h}$ in infected animals, suggesting that $\mathrm{LP}_{\mathrm{PIII}}$ also played a role in activating the later inflammatory response. ${ }^{(17)}$

Corroborating with the increase in neutrophil numbers in the peritoneal cavity, the treatment with LP $_{\text {PIII }}$ caused significant reduction in bacterial load in the peritoneal fluid within $24 \mathrm{~h}$, furthermore, after $72 \mathrm{~h}$ there was a consistent decrease in bacteria enumeration (3 - 4 $\log \mathrm{CFU} / \mathrm{mL}$ ) in the peritoneal cavity, compared to the infected PBS group of animals (Fig. 4). A significant re- duction in bacterial load was also observed in the blood after $72 \mathrm{~h}$. The early recruitment of neutrophils caused by $\mathrm{LP}_{\mathrm{PIII}}$ primed the cellular immunity in the site of infection, reducing the bacterial load. This effect probably contributed to protecting the animals against septic shock, and this is well represented in the survival rate observed. As seen in past studies, the numbers of $S$. Typhimurium CFU increases in the organs that are their target of the infection, such as spleen and liver. ${ }^{(18)}$ The results observed in Fig. 4 suggest that despite the initial reduction of bacteria load in the peritoneal cavity of animals treated with $\mathrm{LP}_{\text {PIII }}$, the load of bacteria in liver and spleen was similar among all survival animals (24 or 72 h). Therefore, the chemiotactic effect displayed by LP over neutrophils was not pivotal to abrogate infection.

Histopathology - $\mathrm{LP}_{\mathrm{PIII}}$ caused moderate inflammatory swelling in liver and spleen. Mononuclear phagocytic system cells were detected in higher than normal amounts, such as Kupffer cells and histiocytes in the liver and spleen, respectively (Fig. 5). Within $24 \mathrm{~h}$ of infection, the animals of PBS group showed signs of intense hydropic degeneration in the liver and focal apoptosis in the spleen, both organs had inflammatory infiltrates. After $72 \mathrm{~h}$ various sites of apoptosis were detected in liver and spleen. Twenty-four hours after infection, animals of the
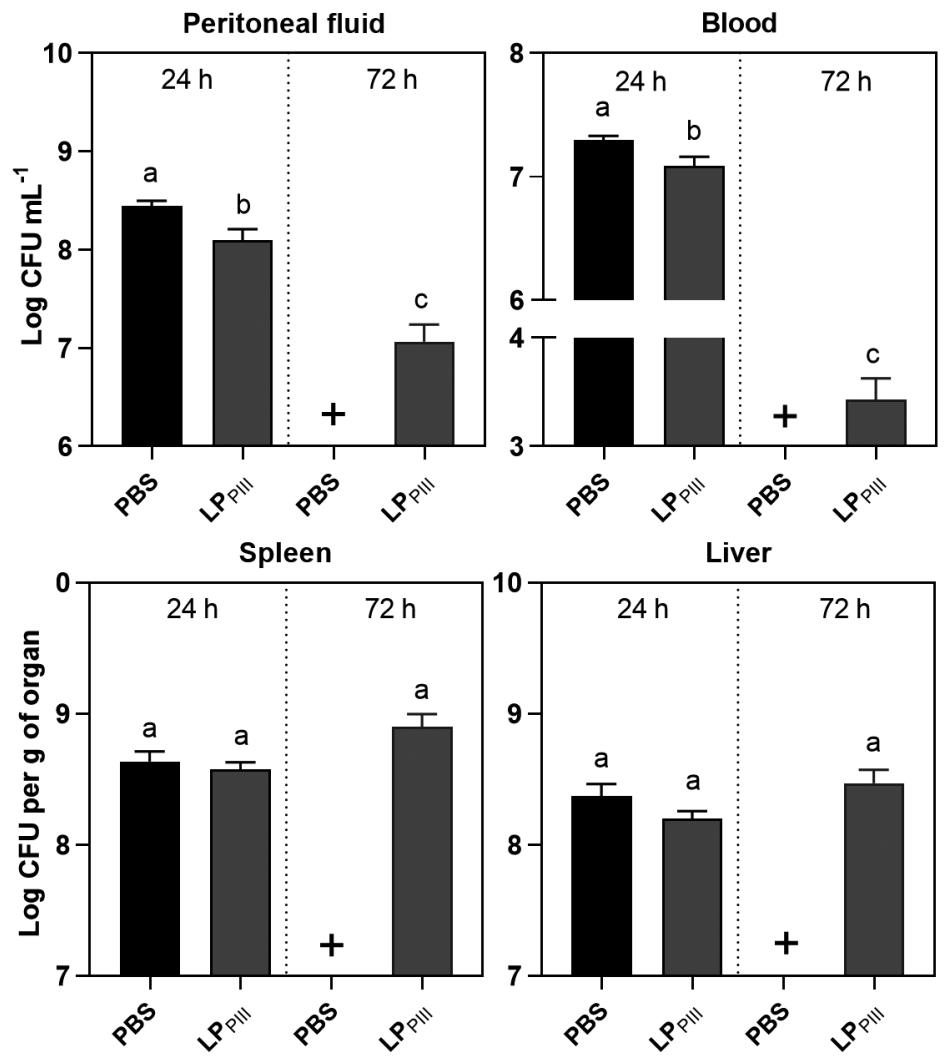

Fig. 4: bacterial enumeration. Animals were treated with $\mathrm{LP}_{\mathrm{PIII}}$ from Calotropis procera $(5 \mathrm{mg} / \mathrm{kg}) 24 \mathrm{~h}$ before lethal infection with Salmonella Typhimurium suspension $\left[0.2 \mathrm{~mL}, 10^{6}\right.$ colony-forming unit (CFU)/mL]. 24- and 72-hours post-infection, blood, peritoneal fluid, spleen, and liver were aseptically collected; fluids were diluted, and organs were homogenised in phosphate-buffered saline (PBS) and plated in Petri dishes with sterile MacConkey agar medium. After $24 \mathrm{~h}$ of incubation at $37^{\circ} \mathrm{C}$, the number of CFU was identified. Values are expressed as mean \pm standard error of mean (SEM) of CFU per milliliter or per gram of organ. The $(+)$ sign indicates that all animals from that group died. Different letters indicate statistically significant differences $(\mathrm{p}<0.05 ; \mathrm{n}=8$, one-way analysis of variance (ANOVA) - Bonferroni test). 

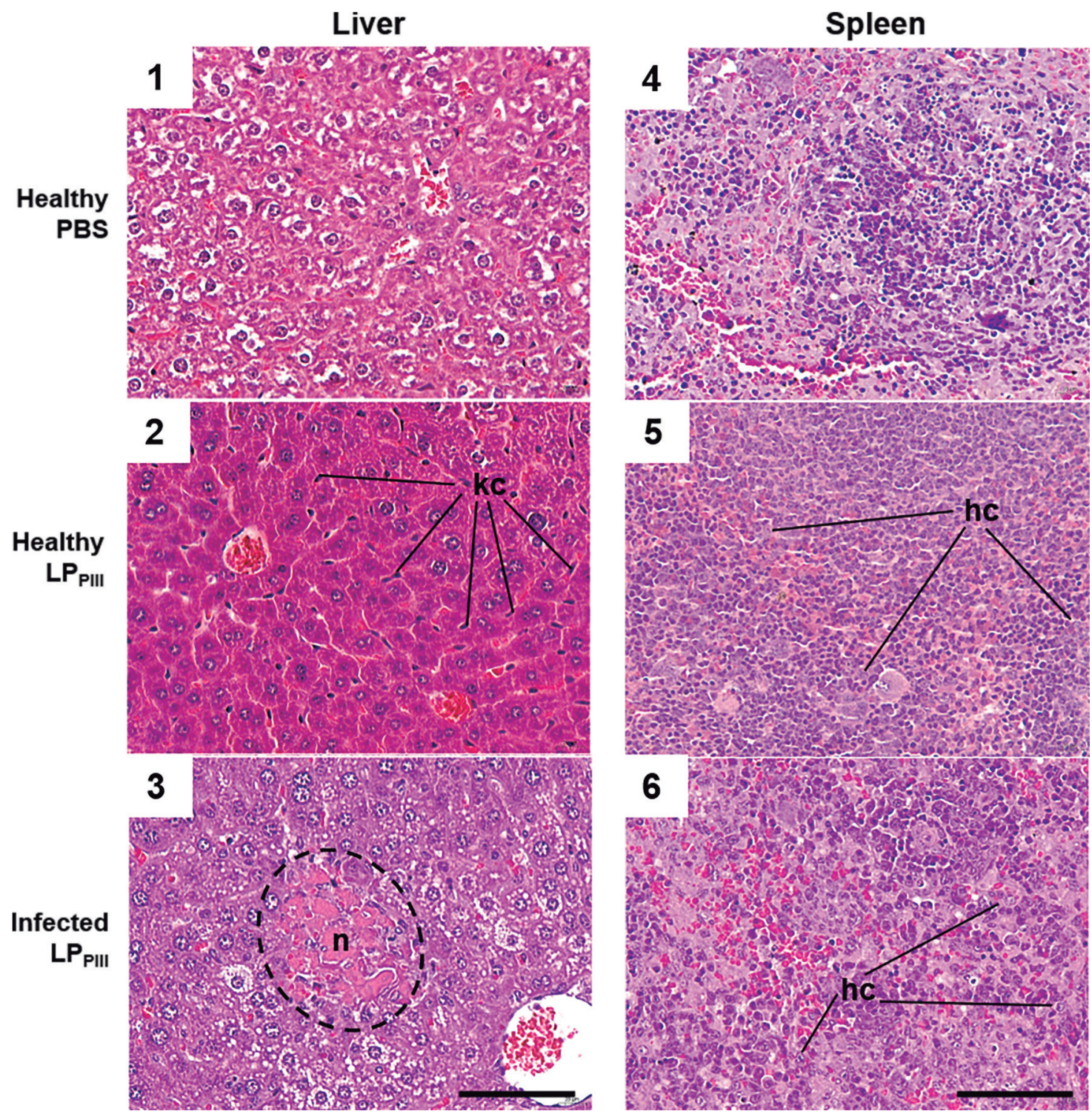

Fig. 5: images of microscopic slides of liver and spleen of healthy animals and infected animal treated or not with $\mathrm{LP}_{\mathrm{PIII}}$. The most representative images of these groups were chosen. Animals were euthanised and the organs were aseptically removed. After fixation and inclusion and paraffin, $5 \mu \mathrm{m}$ cuts were done in a microtome. The cuts were fixated in microscope slides and stained with hematoxylin and eosin for the analysis of inflammatory infiltration and organ architectural damage. kc: Kupffer cells; n: necrosis; hc: histiocytes.

$\mathrm{LP}_{\mathrm{PIII}}$ group exhibited highly spread Kupfer hyperplasia and histiocytosis in the liver and spleen, respectively. After $72 \mathrm{~h}$, there was a high number of neutrophilic infiltrations in the liver and moderate apoptosis in both organs.

Kupffer cells has a pivotal role in starting and controlling systemic inflammation. Kupffer cells release IL-10, an anti-inflammatory cytokine that quickly disperse in the circulation through the hepatic vasculature. Besides that, these cells can neutralise bacteria by means of nitric oxide and reactive oxygen species, serving as an important barrier against invasive bacteria such as $S$. Typhimurium ${ }^{(19)}$ The increase in Kupffer cells in liver, caused by $\mathrm{LP}_{\mathrm{PIII}}$ treatment probably afforded means to the control of bacterial load in the organs, and helped increasing circulating levels of IL-10.
Cytokines - The cytokines TNF- $\alpha$, IL-1 $\beta$ and IL-10 were measured due to their central role in the inflammatory process. The levels of TNF- $\alpha$ did not change neither $24 \mathrm{~h}$ after $\mathrm{LP}_{\mathrm{PIII}}$ administration in healthy animals, nor 24 $\mathrm{h}$ after bacterial infection, both in the peritoneal cavity and in the blood. However, TNF- $\alpha$ concentration in the peritoneal fluid was significantly higher in animals that received the protein administration before the infection, although in the blood, this same group exhibited significantly lower levels of TNF- $\alpha$ (Fig. 6). The levels of IL-1 $\beta$ in the peritoneal fluid of healthy animals treated with LPPII did not change. During infection, the PBS group had a 5-fold increase in concentration, while the $\mathrm{LP}_{\mathrm{PIII}}$ group exhibited a 16 -fold increase. In the blood, IL-1 $\beta$ levels decreased in healthy $\mathrm{LP}_{\mathrm{PIII}}$ group. During infection, the 
concentration of IL-1 $\beta$ decreased significantly for PBS and $\mathrm{LP}_{\mathrm{PIII}}$ groups (Fig. 6). There was no change in IL-10 in the peritoneal cavity of the different groups. However, in the blood, the administration of $\mathrm{LP}_{\text {PIII }}$ in healthy and infected animals caused a significant increase in the cytokine's level (Fig. 6). This increase may be related to the increase in Kupffer cells caused by $\mathrm{LP}_{\mathrm{PIII}}$ administration.
Nitric oxide - In the peritoneal cavity, the administration of $\mathrm{LP}_{\text {PIII }}$ lowered the $\mathrm{NO}$ release within $24 \mathrm{~h}$. After $72 \mathrm{~h}$, the concentration remained the same in these animals. During infection, infected-only animals had higher concentrations of this inflammation mediator in the peritoneal cavity, while treated and infected animals exhibited valued lower than the infected-only group but higher
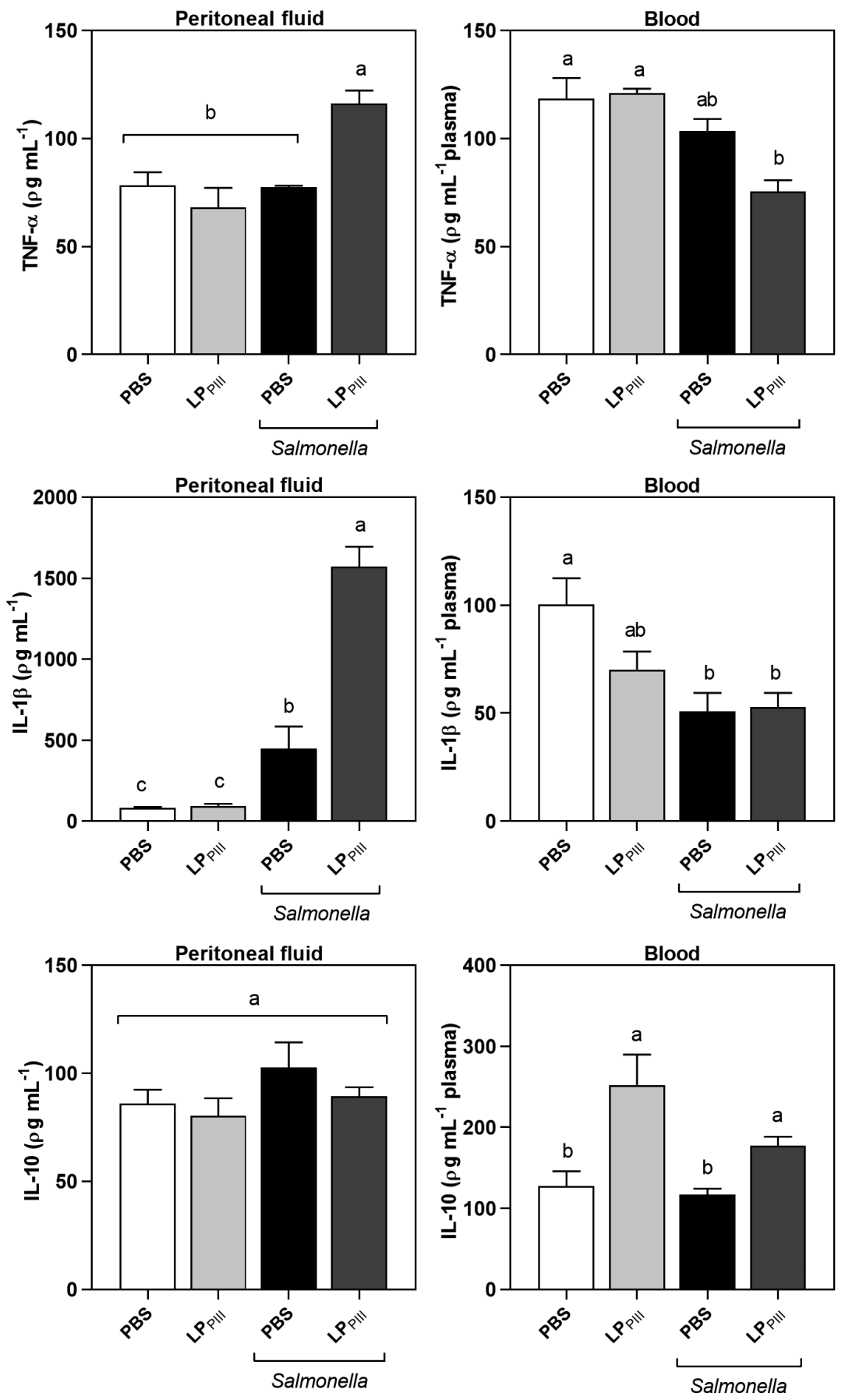

Fig. 6: measurement of TNF- $\alpha$, IL-1 $\beta$ and IL-10 in the peritoneal fluid and blood plasma of mice treated or not with $\mathrm{LP}_{\mathrm{PIII}}$, infected or not by Salmonella. After $24 \mathrm{~h}$ of infection, blood and peritoneal fluid were collected and the cytokines were measured using mouse enzyme-linked immunosorbent assay (ELISA) kits. Values are expressed as mean \pm standard error of mean (SEM) of $\rho g$ of cytokine per mL of fluid or plasma. The $(+)$ sign indicates that all animals from that group died. Different letters indicate statistically significant differences $(\mathrm{p}<0.05 ; \mathrm{n}=8$, oneway analysis of variance (ANOVA) - Bonferroni test). 
than the control. After $72 \mathrm{~h}$, the NO levels in treated and infected animals exhibited significantly higher concentrations (Fig. 7). In the blood, it is observed that the administration of $\mathrm{LP}_{\mathrm{PIII}}$ did not change the levels of NO in healthy animals that received the protein i.p. Treated and infected animals did not exhibit changes in NO concentration within $24 \mathrm{~h}$, but after $72 \mathrm{~h}$ it was lowered (Fig. 7). The treatment with $\mathrm{LP}_{\mathrm{PIII}}$ lowered the NO levels in healthy mice. This reduction also happened during infection that probably helped controlling the oxidative stress.

Plasma coagulation - The treatment with $\mathrm{LP}_{\mathrm{PIII}}$ in healthy mice did not alter blood coagulation time. During infection, the animals of the PBS group had a reduction in total plasma coagulation time, while $\mathrm{LP}_{\mathrm{PII}}$ group strongly slowed the coagulation time within $24 \mathrm{~h}$ and 72 h (Fig. 8). The treatment only had an effect over plasma coagulation during the infection. To further investigate the effect of the treatment over different coagulation cascades, PT and aPTT assays were executed.

In PT assay, the treatment with $\mathrm{LP}_{\mathrm{PIII}}$ increased coagulation time in healthy and infected animals within 24 h. In aPTT assay, the treatment did not change the coagulation time of healthy or infected animals. This suggests that the effect of $\mathrm{LP}_{\mathrm{PIII}}$ over the plasma coagulation happened in the extrinsic pathway that is dependent on tissue factor signaling. During chronic bacterial infections, the disseminated intravascular coagulation starts via tissue factor signaling. ${ }^{(20)}$

Altered levels of inflammatory cytokines, neutrophils and macrophages indicate whether an acute inflammatory process is established. This scenario activates the tissue factor signaling pathway. However, as shown in these results, the treatment with $\mathrm{LP}_{\mathrm{PII}}$ created a local and brief inflammatory response and a later systemic anti-inflammation signaling, through IL-10 release in the blood. Both events seemed to contribute to face the spread of the bacteria infection through the blood, avoiding the activation of the extrinsic coagulation pathway.

\section{DISCUSSION}

This study contributes to the knowledge of the role of $C$. procera LP in modulating the inflammatory process during infections mediated by bacteria. The results presented here demonstrated that despite of the total latex proteins fraction from $C$. procera afford protection to infected animals, this action was not restricted to the subfraction $\mathrm{LP}_{\mathrm{P}}$, as described previously. $\mathrm{LP}_{\mathrm{PII}}$ on the other hand, was demonstrated here that it was also effective in helping animals to overcome the experimental acute bacterial infection.

Furthermore, here it was demonstrated that the protection afforded by $\mathrm{LP}_{\mathrm{PII}}$ was statistically similar to LPPII treated with IAA, a classical reducing agent of disulfide bonds. IAA irreversible inhibits proteolysis of cysteine peptidases. However, it also reduces cysteine residues not involved in proteolysis and potentially disrupt protein structures. This observation suggested that the effectiveness of $\mathrm{LP}_{\mathrm{PIII}}$ was not related to proteolysis. Further experimental approaches are needed to a better comprehension of this aspect.

The single administration (i.p.) of $\mathrm{LP}_{\mathrm{PII}}$ in healthy animals induced neutrophil migration to the administration locus. Thus, at the beginning of the infectious process, $\mathrm{LP}_{\mathrm{PIII}}$ may have facilitated phagocytosis, by recruiting inflammatory cells. The chemotactic effect of $\mathrm{LP}_{\mathrm{PIII}}$ over neutrophils resulted in bactericidal activity mediated by NO release. Also, it is expected that activated neutrophils forwarded the immune response through pro-inflammatory cascade. However, bacterium was not cleared in spleen and liver. In these target organs, the bacteria caused moderate histological damage. The in-
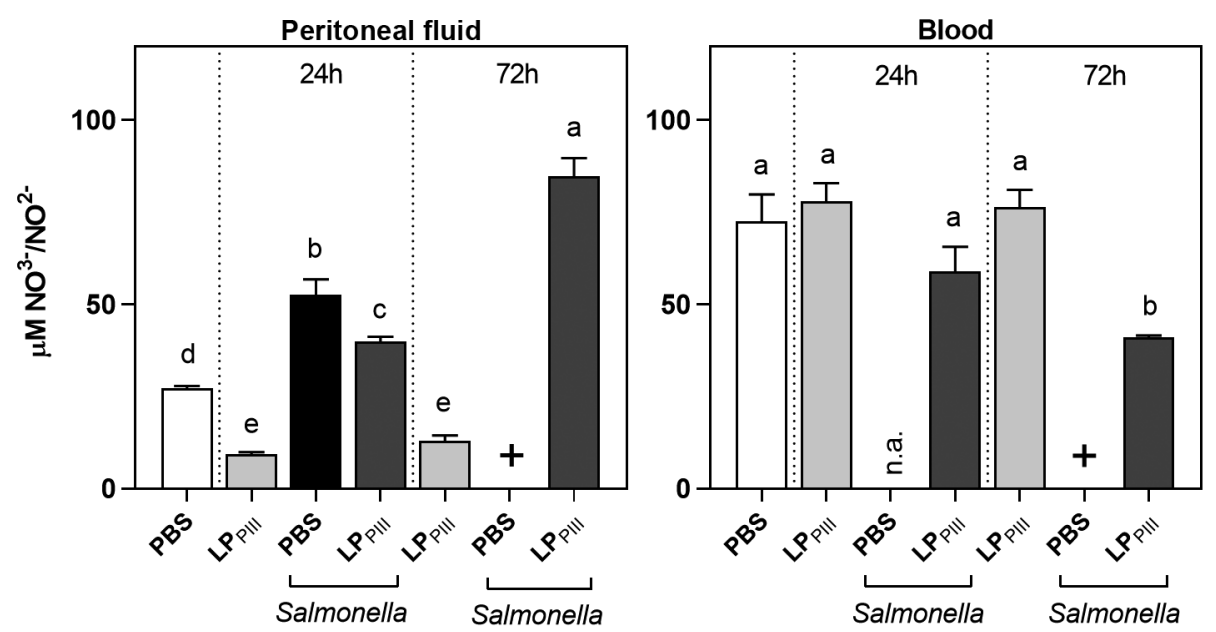

Fig. 7: indirect measurement of nitric oxide (NO) by detecting $\mathrm{NO}^{3-}$, in the peritoneal fluid and blood plasma of treated and untreated, infected, and uninfected mice. Animals received Calotropis procera $\mathrm{LP}_{\mathrm{PIII}}(5 \mathrm{mg} / \mathrm{kg}) 24 \mathrm{~h}$ before infection with Salmonella Typhimurium suspension [0.2 $\mathrm{mL}, 10^{6}$ colony-forming unit $(\mathrm{CFU}) / \mathrm{mL}$. Blood and peritoneal fluids were collected $24 \mathrm{~h}$ and $72 \mathrm{~h}$ after infection. Values are expressed as mean \pm standard error of mean (SEM) of $\mu \mathrm{M}$ of $\mathrm{NO}^{3-} / \mathrm{NO}^{2-}$. Labels (n.a.) indicates that data from that group was not available due to experimental constrains. The $(+)$ sign indicates that all animals from that group died. Different letters indicate statistically significant differences $(p<0.05$; $\mathrm{n}=8$, one-way analysis of variance (ANOVA) - Bonferroni test). 

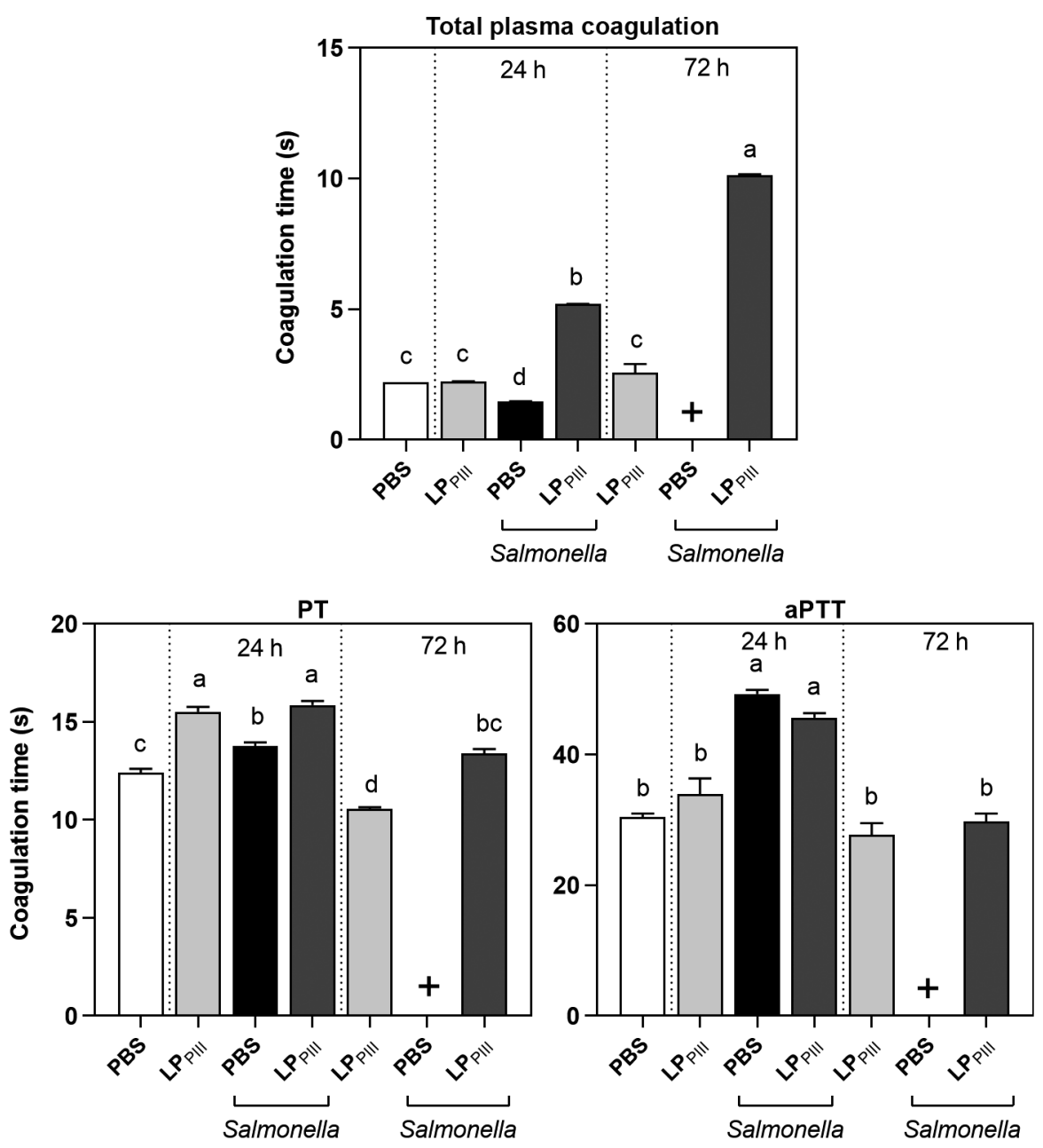

Fig. 8: effect of $\mathrm{LP}_{\mathrm{PIII}}$ from Calotropis procera on total plasma coagulation and involvement in prothrombin (PT) and activated partial thromboplastin time (aPTT) in infected and uninfected Swiss mice. Animals were treated by intraperitoneal route with $5 \mathrm{mg} / \mathrm{kg} \mathrm{LP} \mathrm{PIII}_{2} 24 \mathrm{~h} \mathrm{before}$ infection $\left[0.2 \mathrm{~mL}, 10^{6}\right.$ colony-forming unit $\left.(\mathrm{CFU}) / \mathrm{mL}\right]$. After 24 - and 72 -hours post-infection, plasma was collected, and coagulation time essays were executed following manufacturer's instructions. Coagulation time was measured as the time between the addition of $\mathrm{CaCl}_{2}$ and the detection of clot formation. Data were expressed as mean \pm standard error of mean (SEM) of coagulation time in seconds. The $(+)$ sign indicates that all animals from that group died. Different letters indicate statistically significant differences $(\mathrm{p}<0.05 ; \mathrm{n}=8$, one-way analysis of variance (ANOVA) - Bonferroni test).

filtration of phagocytic cells, detected in these organs, was due $\mathrm{LP}_{\mathrm{PIII}}$ treatment. Therefore, this event possible triggered expression and release of IL-10 in the blood. Elevated level of IL-10 in the blood may have a pivotal role in controlling inadequate inflammation, typically observed in the course of uncontrolled bacterial infections.

TNF- $\alpha$ signals many cell functions critical to the inflammatory response such as proliferation, differentiation, survival, and apoptosis. It is mainly produced by macrophages, which are highly sensitive to TNF- $\alpha$. This cytokine plays a regulator role in commanding other inflammatory cytokines production. ${ }^{(21)}$ The C. procera $\mathrm{LP}$ and $\mathrm{LP}_{\mathrm{PI}}$ administration in the peritoneal cavity was shown to induce TNF- $\alpha$ production within $4 \mathrm{~h}$ post-infection, due to the induction of NO, while non treated and infected animals had a delayed production of this cytokine ${ }^{(6)}$ In our experiment, the administration of LPPIII did not cause release of TNF- $\alpha$, detected at $24 \mathrm{~h}$, in the peritoneal cavity.
Although TNF- $\alpha$ plays a pivotal role in initiating the inflammatory response, other cytokines oversee the persistence of the inflammation. For example, TNF acts as transcriptional regulator of inflammasome components. An inflammasome is a protein complex that is responsible of producing the active mature form of inflammatory cytokines, such as IL-1 $\beta .^{(22)}$ Here, it was demonstrated that animals infected with Salmonella exhibited significantly high levels of IL-1 $\beta$ in the peritoneal cavity, coming from the inflammatory response against the infection. ${ }^{(23)}$ This cytokine will activate inflammatory tissue and recruit macrophages and neutrophils, similar to observed with $\mathrm{LP}_{\mathrm{PI}}{ }^{(3)}$

Salmonella causes the release of chemokines and cytokines that provoke a local inflammatory response, attracting neutrophils and macrophages to use as a new host to disseminate itself through the body. Whereas Salmonella survives inside macrophages, neutrophils are able to kill the bacteria, due to the high concentra- 
tion of ROS in the phagosome of these cells. ${ }^{(24)}$ In fact, the neutrophil numbers in animals treated with $\mathrm{LP}_{\mathrm{PIII}}$ increased significantly, coordinated with the release of IL-1 $\beta$, that acted recruiting these cells, resulting in the reduction in bacteria numbers at the site of infection.

Among the cytokines produced during severe bacteremia, IL-10 acts as an immunoregulatory molecule. It is produced by various leukocytes including neutrophils and $\mathrm{T}$ cells, and it down-regulates signaling receptors that reverts the inflammation progress, including halting immune cell proliferation, antigen presentation and inhibition of oxidative burst. During bacterial infection, the time at which IL-10 is produced and released may have harmful results and contribute to organ damage, reduced bacterial clearance and overall lower survival rates, because the inhibition of the inflammatory response can allow pathogens to escape immune control, causing rapid dissemination of the pathogen to vital organs resulting in fatal infections. ${ }^{(25)}$ In this experiment, $\mathrm{LP}_{\mathrm{PIII}}$ caused an increase in IL-10 in the blood regardless healthy or infected animals. This early release of circulating IL-10 in the blood was essential in avoiding the exacerbation of the inflammation caused by Salmonella, allowing more time for leukocyte migration and phagocytosis of bacteria. However, high levels of this cytokine impairs pathogen clearance while ameliorating organ damage. ${ }^{(25)}$ This effect was seen in this study, in animals that received LPPIII, bacteria levels did not decrease in organs, while the level of tissue disarray was lower compared to animals of infected PBS group.

The inflammatory response, mediated by immune cells, against severe and uncontrolled infections, results in cell death and organ damage, and ultimately the disseminated intravascular coagulation: the septic shock. NO is a signaling molecule that have defensive roles against infectious diseases but also has harmful effects over the organism. ${ }^{(26)} \mathrm{NO}$ was found to be essential in enhancing survival of mice infected by Salmonella Typhimurium. ${ }^{(27)}$ In this study, NO levels were reduced in healthy animals treated with $\mathrm{LP}_{\mathrm{PIII}}$ : This reduction was also observed in treated infected animals. Therefore, LPPIII also contributed to modulate NO release. The control of the oxidative stress during the infection prevented further damage and exacerbation of the inflammation.

The same inflammatory regulators which result in a systemic response, also activates the coagulation system. Previous studies have demonstrated that $C$. procera LP reduces the clotting time ${ }^{(10)}$ and is able to change the fluid nature of the blood from pseudoplastic to Bingham fluid which means that it reduces the blood fluidity increasing its viscosity. However, these effects seem to be transient and do not lead animals to death. ${ }^{(28)}$ Here, it was used a subfraction of that sample and it was not observed any alteration in the total blood coagulation time in healthy animals. The infection caused the reduction in coagulation time. Treated-infected animals exhibited higher coagulation time. Moreover, the administration of $\mathrm{LP}_{\mathrm{PIII}}$ in healthy animals increased extrinsic coagulation time. This reveals that the influence of $C$. procera LP over the coagulation system is dependent on the subfraction analysed and that $\mathrm{LP}_{\mathrm{PIII}}$ has an action only over the tissue factor (TF) signaling coagulation pathway. A prolonged PT is related to levels of factor VII, its synthesis can be reduced due to liver damage or increased consumption, due to coagulopathies. ${ }^{(29)}$

In addition, $\mathrm{LP}_{\mathrm{PIII}}$ was previously described as containing peptidases with both thrombin- and plasmin-like activities in vitro. ${ }^{(10)}$ It was demonstrated here that this subfraction has an anti-coagulant activity in vivo, during the infectious process, by increasing coagulation time in infected animals. When analysing extrinsic and intrinsic coagulation pathways, the protein inoculation likely affected TF signaling, due to the increase in prothrombin coagulation time $24 \mathrm{~h}$ after infection. TF is produced by activated macrophages and monocytes, as well as endothelial cells and organ capsules and its expression is upregulated by proinflammatory cytokines. ${ }^{(20)}$

In conclusion, $\mathrm{LP}_{\mathrm{PIII}}$ demonstrated to afford protection against lethal infection induced by Salmonella. As previously observed for $\mathrm{LP}_{\mathrm{PI}}$, the survival of animals treated with $\mathrm{LP}_{\mathrm{PII}}$ or $\mathrm{LP}_{\mathrm{PIII}}$ was lower than that observed to LP. Therefore, it is proposed that the full protection observed, when animals are treated with LP, is due synergism effect of different proteins found in the different subtractions of LP (i.e. $\mathrm{LP}_{\mathrm{PI}}, \mathrm{LP}_{\mathrm{PII}}, \mathrm{LP}_{\mathrm{PIII}}$ ). Experimental evidences suggest that different contributions, belonging to different proteins, underlying specific pathways of action provide LP the efficiency for full protection against different inflammatory stimulus. In the case of $\mathrm{LP}_{\mathrm{PIII}}$, the recruitment of inflammatory cells to the primary site of infection seems to play an important role to control infection. The observed increment of the antiinflammatory IL-10 cytokine, in the blood, would play a pivotal effect against bacterial lethality. Lastly, the observation that $\mathrm{LP}_{\mathrm{PIII}}$ contributes to slow down blood coagulation in septic animals, through modulation of the extrinsic pathway, would explain the absence of clinical signs of disseminated intravascular coagulation, the ultimate physiological event documented in septic death. The pathway leading to IL-10 production through $\mathrm{LP}_{\mathrm{PIII}}$ treatment remains fully unknown.

\section{AUTHORS' CONTRIBUTION}

BFS, AFBS and MVR designed and conducted the research; DNO analysed the histological data; AGA performed cell counting and differentiation; JVML, CDTF, NMNA, BFS and AFBS contributed to the protein extraction and microbial manipulation. All authors wrote and revised the manuscript.

\section{REFERENCES}

1. Ramos MV, Grangeiro TB, Freire EA, Sales MP, Souza DP, Araújo ES, et al. The defensive role of latex in plants: detrimental effects on insects. Arthropod Plant Interact. 2010; 4(1): 57-67.

2. Aderounmua A, Omonisib A, Akingbasotec J, Makanjuolad M, Bejide R, Orafidiya L, et al. Wound-healing and potential antikeloidal properties of the latex of Calotropis procera (aiton) Asclepiadaceae in rabbits. African J Tradit Complement Altern Med. 2013; 10(3): 574-9.

3. Viana CA, Ramos MV, Marinho Filho JDB, Lotufo LVC, Figueiredo IST, de Oliveira JS, et al. Cytotoxicity against tumor cell lines and anti-inflammatory properties of chitinases from Calotropis procera latex. Naunyn Schmiedebergs Arch Pharmacol. 2017; 390(10): 1005-13. 
4. Sangraula H, Dewan S, Kumar VL. Evaluation of anti-inflammatory activity of latex of Calotropis procera in different models of inflammation. Inflammopharmacology. 2001; 9(3): 257-64.

5. Freitas CDT, Oliveira JS, Miranda MRA, Macedo NMR, Sales MP, Villas-Boas LA, et al. Enzymatic activities and protein profile of latex from Calotropis procera. Plant Physiol Biochem. 2007; 45(10-11): 781-9.

6. Oliveira RSB, Figueiredo IST, Freitas LBN, Pinheiro RSP, Brito GAC, Alencar NMN, et al. Inflammation induced by phytomodulatory proteins from the latex of Calotropis procera (Asclepiadaceae) protects against Salmonella infection in a murine model of typhoid fever. Inflamm Res. 2012; 61(7): 689-98.

7. Alencar NMN, Oliveira JS, Mesquita RO, Lima MW, Vale MR, Etchells JP, et al. Pro- and anti-inflammatory activities of the latex from Calotropis procera (Ait.) R.Br. are triggered by compounds fractionated by dialysis. Inflamm Res. 2006; 55(12): 559-64.

8. Kumar VL, Chaudhary P, de Araújo Viana C, Ramos MV. Antiedematogenic and antioxidant properties of high molecular weight protein sub-fraction of Calotropis procera latex in rat. J Basic Clin Pharm. 2015; 6(2): 69-73.

9. Lima-Filho JV, Patriota JM, Silva AFB, Filho NT, Oliveira RSB, Alencar NMN, et al. Proteins from latex of Calotropis procera prevent septic shock due to lethal infection by Salmonella enterica serovar Typhimurium. J Ethnopharmacol. 2010; 129(3): 327-34.

10. Ramos MV, Viana CA, Silva AFB, Freitas CDT, Figueiredo IST, Oliveira RSB, et al. Proteins derived from latex of Calotropis procera maintain coagulation homeostasis in septic mice and exhibit thrombin- and plasmin-like activities. Naunyn Schmiedebergs Arch Pharmacol. 2012; 385(5): 455-63.

11. Ramos MV, Freitas APF, Leitão RFC, Costa DVS, Cerqueira GS, Martins DS, et al. Anti-inflammatory latex proteins of the medicinal plant Calotropis procera: a promising alternative for oral mucositis treatment. Inflamm Res. 2020; 69(9): 951-66.

12. Bezerra CF, Mota ÉF, Silva ACM, Tomé AR, Silva MZR, de Brito $\mathrm{D}$, et al. Latex proteins from Calotropis procera: toxicity and immunological tolerance revisited. Chem Biol Interact. 2017; 274: $138-49$.

13. Laemmli UK. Cleavage of structural proteins during the assembly of the head of bacteriophage T4. Nature. 1970; 227(5259): 680-5.

14. Souza GEP, Ferreira SH. Blockade by antimacrophage serum of the migration of PMN neutrophils into the inflamed peritoneal cavity. Agents Actions. 1985; 17(1): 97-103.

15. Chao CC, Hu S, Sheng WS, Bu D, Bukrinsky MI, Peterson PK. Cytokine-stimulated astrocytes damage human neurons via a nitric oxide mechanism. Glia. 1996; 16(3): 276-84.
16. Abdool GM. The white cell count in typhoid fever. Trop Geogr Med. 1992; 44(1-2): 23.

17. Ramos MV, Oliveira JS, Figueiredo JG, Figueiredo IST, Kumar $\mathrm{VL}$, Bitencourt FS, et al. Involvement of NO in the inhibitory effect of Calotropis procera latex protein fractions on leukocyte rolling, adhesion and infiltration in rat peritonitis model. J Ethnopharmacol. 2009; 125(3): 387-92.

18. Janis C, Grant AJ, McKinley TJ, Morgan FJE, John VF, Houghton $\mathrm{J}$, et al. In vivo regulation of the Vi antigen in Salmonella and induction of immune responses with an in vivo-inducible promoter. Infect Immun. 2011; 79(6): 2481-8.

19. De Andrade DR, De Andrade Jr DR. Typhoid fever as cellular microbiological model. Rev Inst Med Trop São Paulo. 2003; 45(4): $185-91$.

20. Levi M, Van Der Poll T. Inflammation and coagulation. Crit Care Med. 2010; 38(2): s26-34.

21. Parameswaran N, Patial S. Tumor necrosis factor- $\alpha$ signaling in macrophages. Crit Rev Eukaryot Gene Expr. 2010; 20(2): 87-103.

22. Yang Y, Wang H, Kouadir M, Song H, Shi F. Recent advances in the mechanisms of NLRP3 inflammasome activation and its inhibitors. Cell Death Dis. 2019; 10(2).

23. Ren K, Torres R. Role of interleukin-1 $\beta$ during pain and inflammation. Brain Res Rev. 2009; 60(1): 57-64.

24. Burton NA, Schürmann N, Casse O, Steeb AK, Claudi B, Zankl J, et al. Disparate impact of oxidative host defenses determines the fate of salmonella during systemic infection in mice. Cell Host Microbe. 2014; 15(1): 72-83.

25. Peñaloza HF, Schultz BM, Nieto PA, Salazar GA, Suazo I, Gonzalez PA, et al. Opposing roles of IL-10 in acute bacterial infection. Cytokine Growth Factor Rev. 2016; 32: 17-30.

26. Nathan C, Shiloh MU. Reactive oxygen and nitrogen intermediates in the relationship between mammalian hosts and microbial pathogens. Proc Natl Acad Sci USA. 2000; 97(16): 8841-8.

27. Yadav S, Pathak S, Sarikhani M, Majumdar S, Ray S, Chandrasekar BS, et al. Nitric oxide synthase 2 enhances the survival of mice during Salmonella typhimurium infection-induced sepsis by increasing reactive oxygen species, inflammatory cytokines and recruitment of neutrophils to the peritoneal cavity. Free Radic Biol Med. 2018; 116: 73-87.

28. Silva AFB, Sousa JS, Cunha PLR, Lima-Filho JV, Alencar NMN, Freitas CDT, et al. Erythrocytes morphology and hemorheology in severe bacterial infection. Mem Inst Oswaldo Cruz. 2019; 114: 1-8.

29. Ramos MV, Araújo ES, Jucá TL, Monteiro-Moreira ACO, Vasconcelos IM, Moreira RA, et al. New insights into the complex mixture of latex cysteine peptidases in Calotropis procera. Int $\mathrm{J}$ Biol Macromol. 2013; 58: 211-9. 